\title{
Discovery Routing Time Speed Comparison of AODV, OLSR and ZRP protocols on MANET
}

\author{
Ery Safrianti \\ Electrical Engineering Department \\ Riau University \\ Pekanbaru, Indonesia \\ esafriant@eng.unri.ac.id
}

\author{
Linna Oktaviana Sari \\ Electrical Engineering Department \\ Riau University \\ Pekanbaru, Indonesia \\ linnaosari@lecturer.unri.ac.id
}

\author{
Tulus Rahayu \\ Electrical Engineering Department \\ Riau University \\ Pekanbaru, Indonesia \\ tulus.rahayu@student.unri.ac.id
}

*corresponding author: Ery Safrianti,esafrianti@eng.unri.ac.id

\begin{abstract}
Mobile Ad hoc Network (MANET) is a wireless network that contains a collection of nodes without infrastructure and interconnected to communicate. MANET works dynamically when a group of nodes moves spontaneously, so the network topology can change quickly and cannot be predicted. It causes changes in wireless network topology according to existing conditions. The node functions in determining the route to be selected. Ad Hoc networks have limited transmission range, so routing is needed to send data over the network. The problem with mobile nodes is that routing must provide a path when the node changes. The speed of a node obtaining information is affected by the routing protocol used in the network. Each routing protocol has different capabilities in network speed, so the discovery routing time for each routing is also different. The selected routing protocols are Ad Hoc OnDemand Distance Vector (AODV), Optimized Link-state (OLSR), and Zone Routing Protocol (ZRP). The aim of this paper is to determine the routing protocol that produces the best routing discovery times among AODV, OLSR, and ZRP. After the data is collected, an analysis is carried out by looking at the routing discovery speed of each routing protocol. The test results show that each of the routing protocols examined, the AODV routing protocol, has a faster routing discovery time than the OLSR and ZRP routing protocols.
\end{abstract}

Keywords-AODV, MANET, OLSR, routing discovery, ZRP

\section{INTRODUCTION}

Telecommunication networks have undergone rapid changes, especially in networks that do not use cables to communicate. Wireless or wireless networks, better known as Ad Hoc, are in high demand compared to wired networks. The advantages of wireless being high mobility and not dependent on cables and fixed connections. Ad Hoc network is a wireless network with several mobile nodes that do not have fixed routing. Each of these nodes can function as a routing that can find and handle the path to other nodes in one network. Each node on the mobile network has a network topology that changes [1]. MANET is a wireless network without infrastructure. It works dynamically when a set of nodes moves spontaneously. MANET topology can change fast and unpredictable according to existing conditions [2].

A routing protocol is a communication between nodes to share data or information relating to a network and connections from one node to another. In the MANET network, the node functions to determine the route to be addressed. There are three categories of routing protocols in ad hoc networks: reactive routing protocols, proactive routing protocols, and hybrid routing protocols. Proactive types, including Destination Sequenced Distance Vector (DSDV), Cluster Switch Gate-away Routing (CSGR), Wireless Routing Protocol (WRP), Optimized Link-state (OSLR). Reactive types, including Dynamic Source Routing (DSR), Ad Hoc OnDemand Distance Vector (AODV), Associative Based Routing (ABR), Signal Stability Routing (SSR). In contrast, the Hybrid type is a combination of Proactive and Reactive, for example, Zone Routing Protocol (ZRP) [3].

Ad Hoc networks have limited transmission range, which causes routing needed to send data over the network. Mobile nodes experience problems in routing; namely, routing must provide a path when the node changes. Therefore, various types of routing protocols have emerged that can overcome this [4]. The preferred routing protocols are AODV, OLSR, and ZRP because each of these types of routing protocols is common and efficient for Ad Hoc networks in their respective routing protocol types. AODV for reactive routing protocol types, OLSR for proactive routing protocol types, and ZRP for hybrid routing protocol types.

The speed at which a node gets information can be affected by the routing protocol used in the network. Each routing protocol can differ in network speed so that the routing discovery time for each route is also different [5]. In this research, an ad hoc network initialization speed analysis will be performed on Ad Hoc On-Demand Distance Vector (AODV) routing protocols, Optimized Link-state (OLSR), and Zone Routing Protocol (ZRP).

Ad Hoc On-demand Distance Vector is a type of reactive protocol. AODV uses two types of operations: route finding (route discovery) and route maintenance (route maintenance). An overview of how AODV works is that the source node will send the closest route request if the node has a path to go, the closest node will reply by responding to the remote reply. [6]

Optimized Link-state Routing (OLSR) is a proactive routing protocol that can immediately provide routing to all existing destination networks. This optimization includes 
classic link states based on multipoint relays (MPR) concepts. Changes in network topology can cause information topology overhead on all nodes in a network [7].

Zone Routing Protocol (ZRP) is a hybrid protocol that proactively manages routes within a local network area. ZRP can be configured for a specific network via a single parameter. IARP refers to a dense network boundary of the proactive routing protocol zone, whereas IERP refers to the outer zone network of the reactive routing protocol [8].

Routing discovery is the ability of a routing protocol to share information about the network with other nodes with the routing protocol used. The selection of the best path on each network is in the routing table using dynamic routing. Routing discovery can be influenced by various factors such as timers, number, position, and movement of nodes [9]. Routing discovery can be influenced by various factors such as time, number of nodes, and node movement. The Discovery time is formed due to the routing table. The routing table is the initial process of forming the time from delivery to the end of delivery.

AWK is a programming language used for text processing and is usually used for data extraction and reporting. AWK is data-driven, containing a set of commands that will be executed on textural data directly in files or used as part of a pipeline [10].

This paper aims to provide a comparative analysis of the discovery time on a MANET network with the AODV, OLSR and ZRP routing protocols. Furthermore, the results of comparison data processing initialization routing discovery time are used to determine the routing protocol with the best delivery speed.

\section{1. RESEARCH METHODS}

\section{A. Research Modeling}

Topology-based routing protocol testing on MANET communication and simulated using NS-2 software with Ubuntu operating system version 18.04. The design begins with determining the network modeling used for the manufacture of topology-based proactive AODV, OLSR, and ZRP routing to be used on the NS-2.

This test will provide routing discovery results. The test was carried out on a device with specifications, as described in Table 1 .

TABLE I. TESTING DEVICE SPECIFICATIONS

\begin{tabular}{|l|l|}
\hline \multicolumn{1}{|c|}{ COMPONENT } & \multicolumn{1}{|c|}{ SPECIFICATIONS } \\
\hline CPU & AMD E1 \\
\hline Hard disk memory & 2 GB \\
\hline Operating system & Ubuntu 16.04 LTS 64 bit \\
\hline RAM & 2 GB RAM \\
\hline Storage & 368 GB \\
\hline NS-2 & v.2.35 \\
\hline
\end{tabular}

In this study, we are using several parameters that are constant, as in Table 2 below.

TABLE II. SIMULATION PARAMETERS

\begin{tabular}{|l|l|}
\hline \multicolumn{1}{|c|}{ Parameters } & \multicolumn{1}{c|}{ Value } \\
\hline Channel Type & Wireless Channel \\
\hline Propagation Method & Two-way ground \\
\hline Network Interface Type & Wireless \\
\hline MAC type & IEEE 802.11 \\
\hline Queue Type & Drop Tail \\
\hline Simulation time & 90 Detik \\
\hline Area & $500 \times 500 \mathrm{~m} 2$ \\
\hline Package Type & TCP \\
\hline
\end{tabular}

\begin{tabular}{|l|l|}
\hline Routing Protocol & AODV/OLSR/ZRP \\
\hline Node movement mode & Random way Point \\
\hline The nodes speed movement & $2 \mathrm{~m} / \mathrm{s}$ \\
\hline
\end{tabular}

\section{B. Simulation Scenarios}

The simulation scenarios used for network speed analysis in the AODV, OLSR, and ZRP routing protocols have the following assumptions.

1. The area required is $500 \times 500 \mathrm{~m} 2$

2. Simulation time 90 seconds

3. The number of nodes 20,30 and 40

4. Package type CBR (Constant Bit Rate)

5. Distance send with the following Pythagoras formula.

$d=\sqrt{\left(x_{2}-x_{1}\right)^{2}+\left(y_{2}-y_{1}\right)^{2}}$

Where:

$\mathrm{d}=$ distance

$\mathrm{x} 1=$ the initial coordinator point on the $\mathrm{x}$-axis

$\mathrm{x} 2=$ the final coordinator point on the $\mathrm{x}$-axis

$\mathrm{y} 1=$ the initial coordinator point on the $y$-axis

$y 2=$ the final coordinator point on the $y$-axis

6. Delivery conditions, namely the position created with the same distance each protocol node, but with random node placement.

To get the results of the discovery time that will be tested, the AWK command is used with a programming language in the form of text processing coupled with the output of the NS2 simulation results in the form of a file with the extension*. tr. To get discovery time, enter the AWK command and mount the convergence awk file with the trace file. The following AWK commands are used:

$$
\text { Awk-f konvergensi.awk trace.tr }
$$

\section{Simulation Process}

At this stage, 20, 30, and 40 nodes are used in each routing protocol. The addition of nodes in each experiment serves to analyze the discovery time for each routing protocol, whether the increase in the number of nodes affects each protocol in the MANET network. The type of node used is random waypoints.

In the simulation process, the script program running according to the protocol used. The scenario has been determined along with the parameters used until the simulation can run and succeed. After the simulation process is complete, the process of finding the discovery routing time using the results of the simulation file is run with a script in the form of awk convergence programming. After the simulation is successfully carried out using the scenario above, the results of the simulation will be obtained data in the form of a.tr file where the data can be used as a benchmark in compiling a routing table to produce a routing discovery.

In the simulation process, the parameters have been continuously set after running with a general script, here is the general configuration program for the * tcl script used in software:

The general configuration program for making * tcl scripts is part of making the characteristics or parameters used for simulation and analysis on MANET. The parameters consist of channel type determination, propagation model, network 
interface, MAC type, link-layer type, antenna model, the area used ( $x$ and $y$ ), number of mobile nodes used, the routing protocol used (AODV, OLSR, and ZRP) and the simulation time. The simulation time is 90 seconds. After determining the characteristics of the NS-2, the next step is to initialize the variables in NS-2, in the Variable Initialization * tcl Script program.

The * tcl script program is used to process variable initialization. The initialization process will produce output to the animator network * nam and trace files to $*$ tr. File $*$ tr is a snapshot of each node's journey. In the initialization process, the simulation area for the opt $(\mathrm{x})$ and opt $(\mathrm{y})$ processes is also determined. If initialization variables have been configured, the next step is to configure the number of nodes and mobility of the nodes in NS-2. After this stage is completed, then the execution stage. At this stage, it contains a closing initialization for testing so that the simulation can be displayed on the NAM, contains the test time and the command to run the simulation. Define Use a zero before decimal points: "0.25", not ".25". Use "cm3", not "cc". (bullet list)

\section{RESUlTS AND DISCUSSION}

Data collection will be carried out by the predetermined simulation planning scenario using the tcl script using predetermined parameters. In this study, the scenario of placing nodes is made randomly between the routing protocols AODV, OLSR, and ZRP. From the experiments carried out will produce data in the form of a table and graphs at each node, and the distance of each scenario will be made the same to produce more specific data for each.

\section{A. Delivery Distance Calculation}

Using the formula (1) the distance of each scenario is calculated so that data such as Table 3 is obtained:

TABLE III. DELIVERY DISTANCE FOR EACH SCENARIO

\begin{tabular}{|c|c|c|c|c|c|}
\hline $\begin{array}{c}\text { Number of } \\
\text { nodes }\end{array}$ & $\begin{array}{c}\boldsymbol{x}_{\boldsymbol{1}} \\
(\mathbf{m})\end{array}$ & $\begin{array}{c}\boldsymbol{x}_{\mathbf{2}} \\
(\mathbf{m})\end{array}$ & $\begin{array}{c}\boldsymbol{y}_{\boldsymbol{1}} \\
(\mathbf{m})\end{array}$ & $\begin{array}{c}\boldsymbol{y}_{\boldsymbol{2}} \\
(\mathbf{m})\end{array}$ & $\begin{array}{c}\text { Delivery distance d } \\
(\mathbf{m})\end{array}$ \\
\hline 20 & 15 & 390 & 420 & 1 & 562,30 \\
\hline 30 & 490 & 20 & 50 & 450 & 617,17 \\
\hline 40 & 400 & 1 & 20 & 410 & 557,94 \\
\hline
\end{tabular}

\section{B. Routing Protocol AODV}

Data collection will be carried out following the predetermined simulation planning scenario using the tcl script using predetermined parameters. In this study, the scenario of placing nodes is made randomly between the routing protocols AODV, OLSR, and ZRP. From the experiments carried out will produce data in the form of a table and graphs at each node, and the distance of each scenario will be made the same to produce more specific data for each.

The following is an image result of the node simulation process that is successfully executed using the software in the AODV routing protocol on the MANET network. In Figure 1 above is the initial simulation time using 20 nodes in the AODV protocol. Node 0 is the sending node, and node 19 is the receiving information node. Figure 2.is a process of 22.24 seconds. The position of the network topology has changed; that is, the distribution of routing discovery for each node is looking for a destination route to forward the delivery to the destination node. At the time of this simulation, the node will perform routing discovery every time it wants to continue sending it to the next few nodes that already have a route based on the AODV protocol.

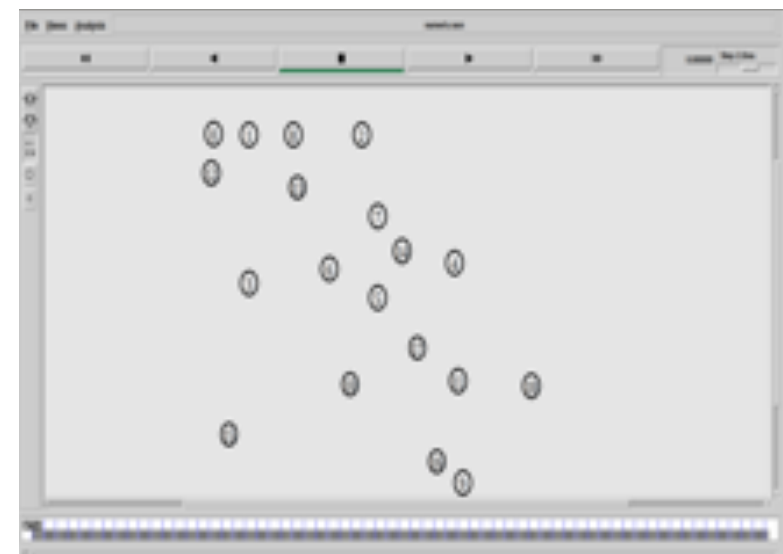

Fig.1. Initial Simulation Process in the AODV Protocol

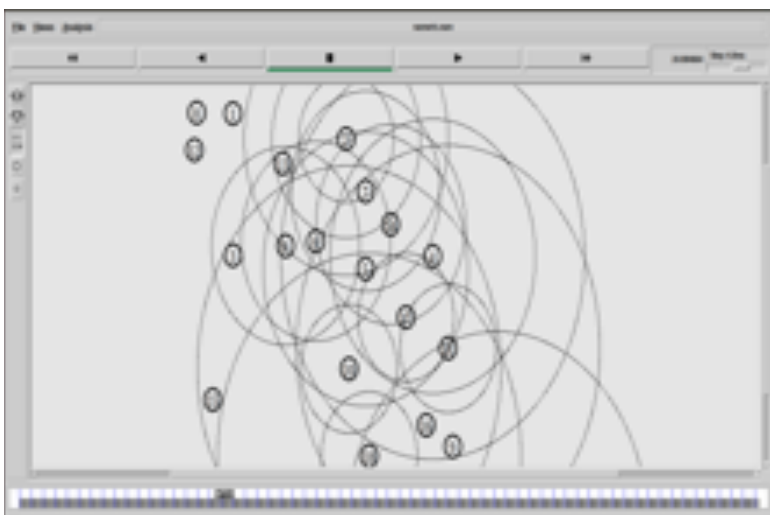

Fig. 2. Process $1 / 4$ Simulation in the AODV Protocol

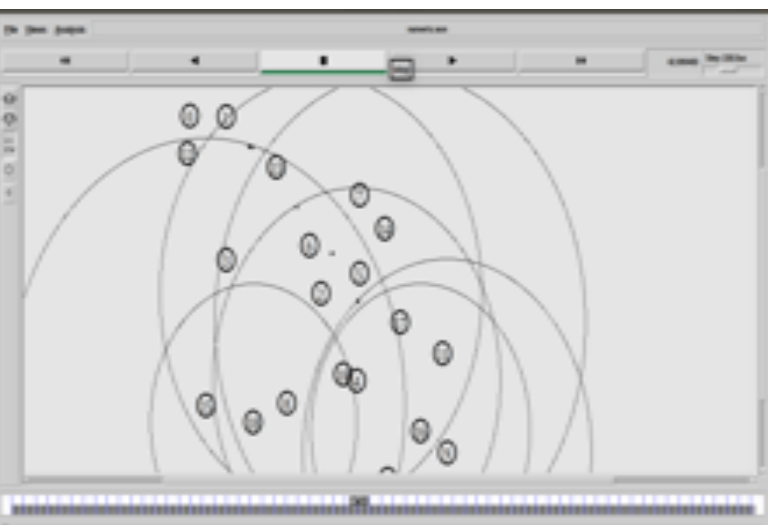

Fig. 3. Half Simulation Process in AODV Protocol

Figure 3, the mid-simulation process of spreading information in the form of a routing table requires some time for selecting any node selected based on the workings of the AODV protocol, namely the intermediary node sending the destination information in the AODV routing protocol. After the distribution process in the delivery already has a route to the destination node, the shipping process will look like in Figure 4 below.

Figure 4 is the final process of the delivery path that has passed through several nodes until the delivery finally arrived at the destination node. The image shows the delivery to node 0 , which continues to node $1,13,6,5,10,8,18$, and the next node until it reaches the destination node, which is 19 . 


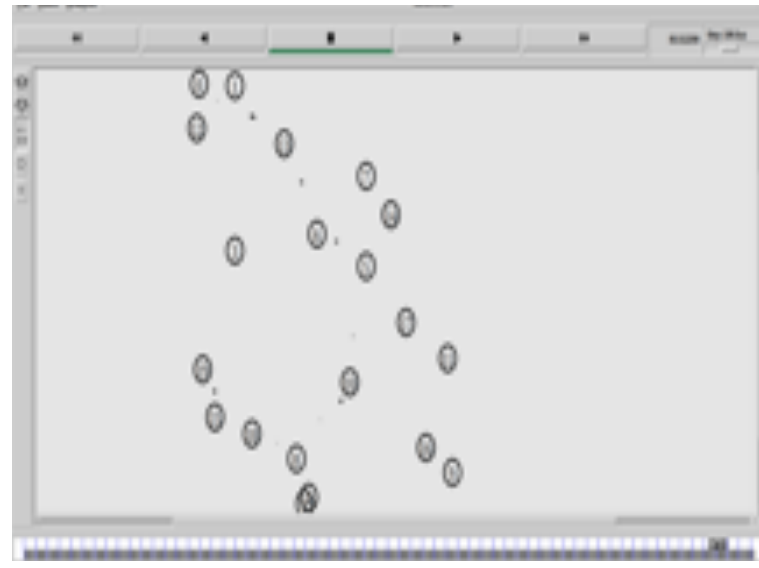

Fig. 4. Final Process of Sending information to the Destination node

\section{Routing Protocol OLSR}

The following is an image result of the node simulation process that was successfully executed using the software in the OLSR routing protocol on the MANET network.

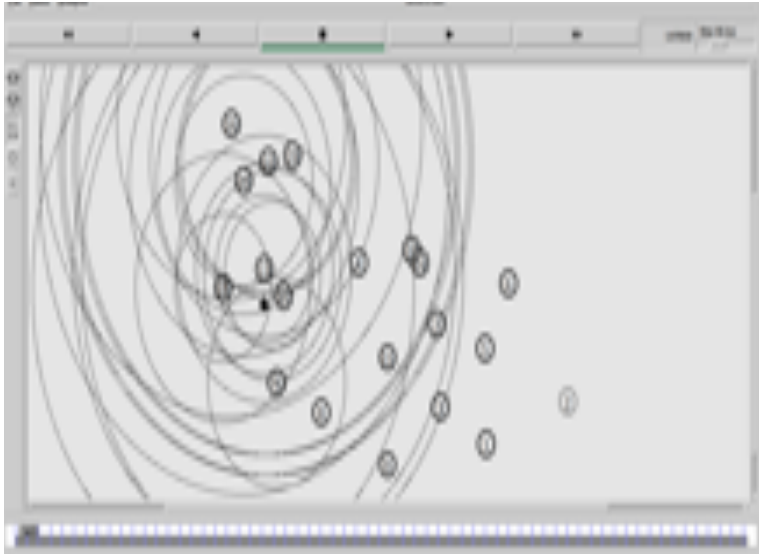

Fig. 5. Initial Simulation Process on the OLSR Protocol

Figure 5 is the initial process of spreading information sending all nodes to filter the nodes included in the MPR node process. MPR node aims to continue sending so that not all nodes do it because it will take time to send the process. At the time of this simulation, the node will discover routing every time it wants to continue sending to the next few nodes that already have a route based on the OLSR protocol through MPR, namely multipoint relay.

Whereas in Figure 6 above is the $1 / 3$ process of simulating sending and receiving selected nodes as the destination MPR mode to continue sending. The OLSR protocol (proactive) method will select a specific router in each connection to notify topology information. The MPR function makes OLSR a unique from link-state routing protocols. The path forwarding information for TC messages is not shared across all nodes. Still, it varies depending on the source, only a subset of source node link-state information, not all links from nodes are notified, only nodes that represent only the selected MPR. Such algorithms are complicated to implement in ad-hoc wireless networks because OLSR does not care about reliability issues. It is enough to disseminate topology information as often as possible to ensure that the database is not updated in a long time.

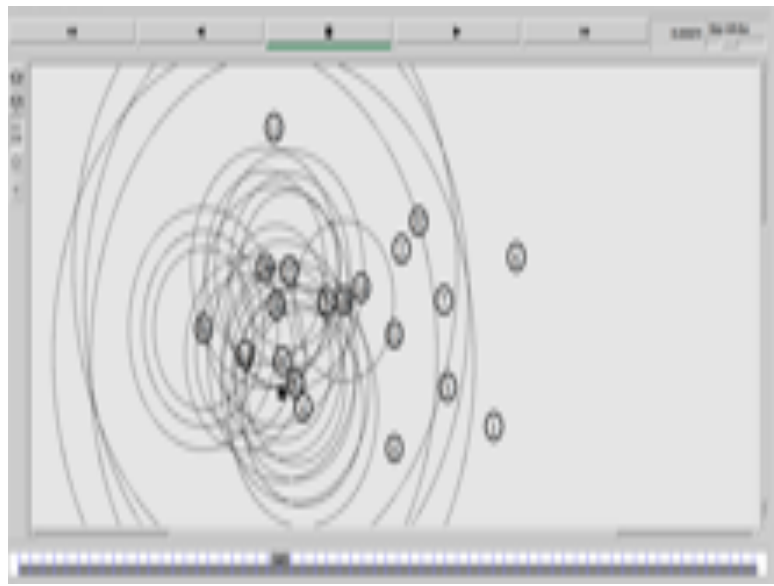

Fig. 6. 1/3 Simulation Process in the OLSR Protocol

In this process, the dissemination of information in the form of a routing table that requires some time for the selection of any node selected based on the workings of the OLSR protocol, namely the intermediary node forwarding the information sent in the OLSR routing protocol. After the distribution process in the delivery already has a route to the destination node, the delivery process will look like in Figure 7 below.

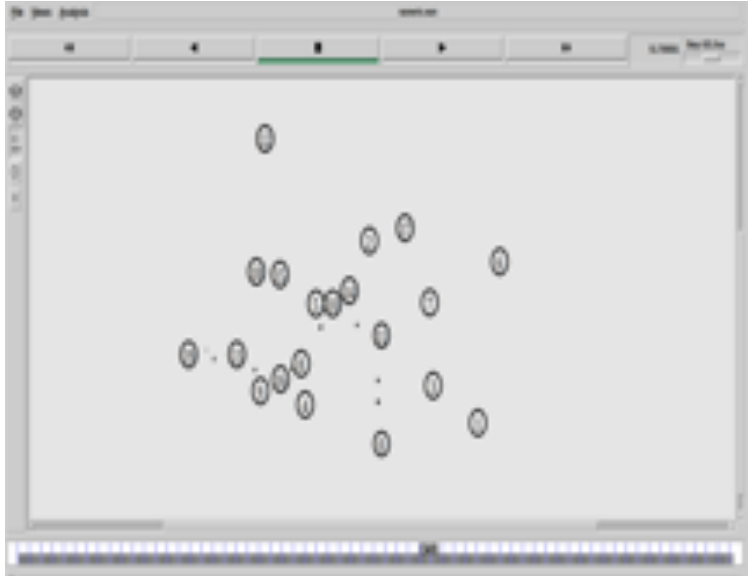

Fig. 7. Half of the OLSR Protocol Simulation

In Figure 7, all nodes will usually broadcast the entire network, allowing the same node to receive the same message more than once, while the MPR will select the node. The MPR is in charge of forwarding messages to other nodes, while nodes that are not MPR nodes will not forward messages to other networks. Thus, minimizing the possibility of the same node getting repeated messages, OLSR is referred to as an update of the link-state version. The OLSR protocol also uses the Neighborhood Discovery system to detect surrounding nodes that have a direct connection. Each node in the OLSR protocol always exchanges topology information with nodes around the MANET network during deployment to select node MPR. Delivery of the OLSR protocol using the MPR method is an effort to reduce the amount of overhead in the network, by using a multipoint relay (MPR) at the surrounding nodes. The goal is to reduce redundant information by selecting several nodes as MPR so that only MPR nodes can forward the received control packets. 


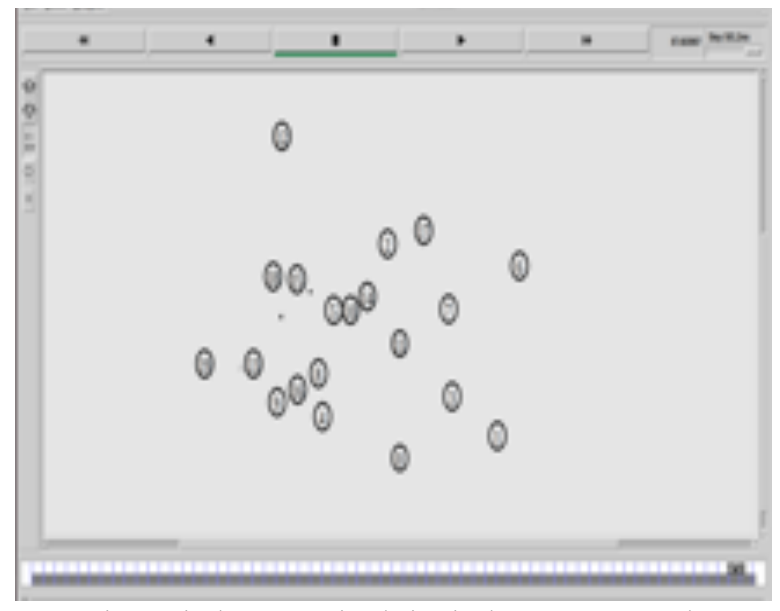

Fig. 8. Final Process Simulation in the OLSR Protocol

\section{Routing Protocol ZRP}

In the simulation, the ZRP protocol has two performances, such as reactive and proactive protocols. The discovery of the route within the zone boundaries uses the workings of the reactive protocol while outside of adultery uses the proactive protocol. The following is an image result of the node simulation process that is successfully executed using the software in the ZRP routing protocol on the MANET network.

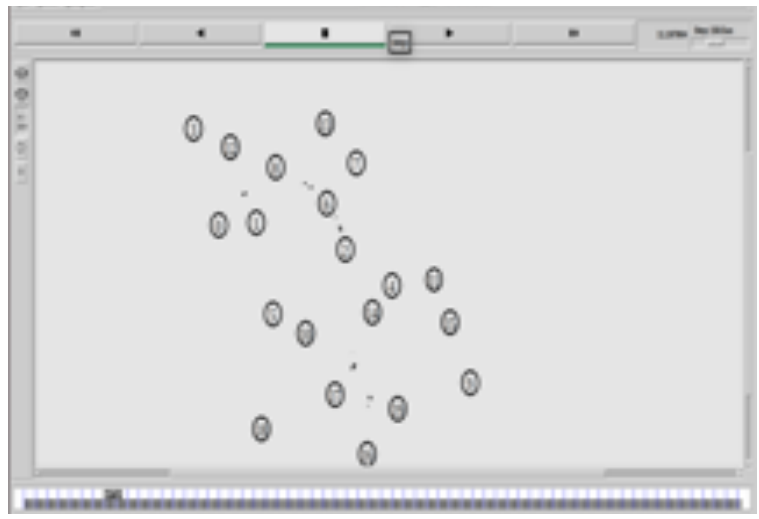

Fig. 9. Initial Simulation Process in the ZRP Protocol

Figure 9 above is the initial simulation process on the ZRP protocol in sending node 0 as the sending node and node 19 as the receiving node. In Figure 10, you can see the distribution of all nodes so that the ZRP protocol can determine which IARP and IERP sub-sectors work based on the division of the zone of proactive protocols and selective protocols in sending in a network. Above is a simulated delimited zone or IERP using a reactive protocol's workings using a stored routing table to send packets immediately. If the route extends outside the zone of the packet's origin, the reactive protocol takes over to check each successive zone in the route to see if the destination is within that zone. This action reduces processing overhead for that route. Once the zone is confirmed contains the destination node, proactive protocol, or stored route list table used for sending packets. In this way, packets with destinations in the same zone as the origin are sent immediately using the stored routing tables. ZRP thereby reduces the control overhead for longer routes that would be required if using a proactive routing protocol across routes while eliminating delays for routing within zones that would be caused by the reactive routing protocol routing process.

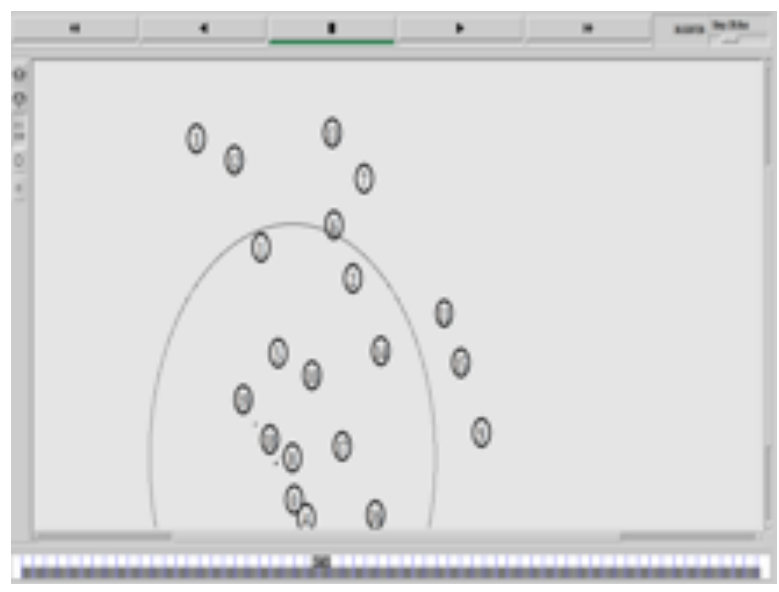

Fig. 10. Half Simulation Process in the ZRP Protocol

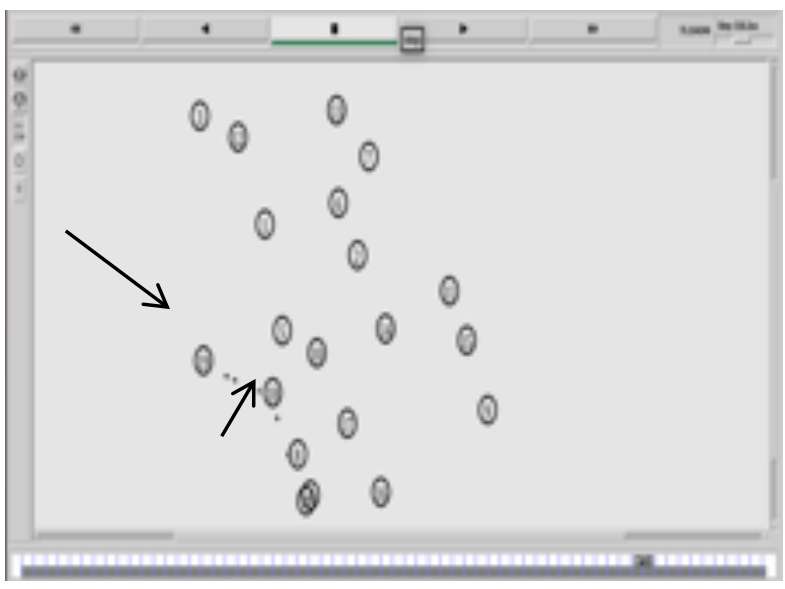

Fig. 11. Process $3 / 4$ Simulation in the ZRP Protocol

Figure 11 above is a simulation process that shows changes in network topology, namely 19 receiving nodes receiving packets from nodes 18 and 8 , which are in one zone.

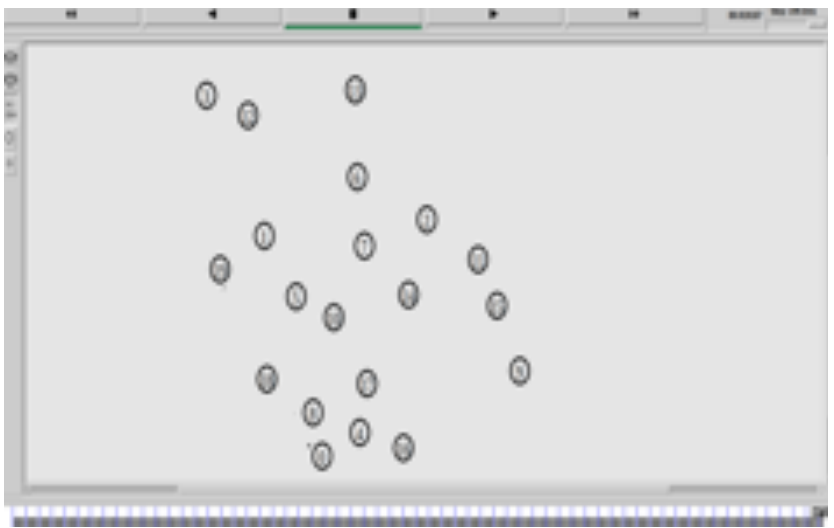

Fig.12. Final Simulation Process in the ZRP Protocol

In Figure 12 above, the final simulation process in this process can be seen again in the difference in the final network topology from the simulation, namely node 19 , which is increasingly moving away from the receiving node, namely node 0 . 


\section{E. Discovery Time Routing Results in AODV, OLSR, and ZRP}

After getting the routing discovery results for each protocol, the results are made in graphical form, as shown in Figure 13 below.

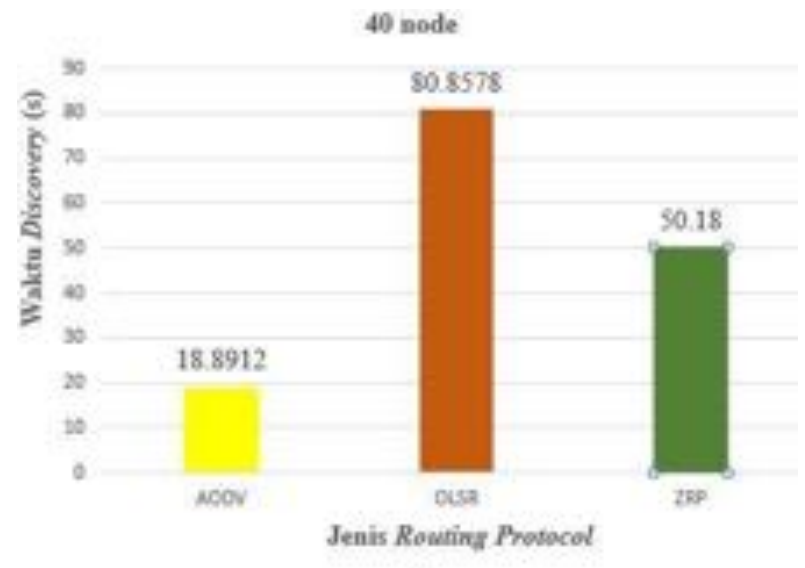

Fig. 13. Graph of Routing Discovery Time on 20 Nodes

From the data above, it can be seen that the AODV routing protocol has the lowest discovery time, namely 10,7089 seconds in the delivery time using 20 nodes. The ZRP protocol is 32.6643 seconds in the delivery time, and the last is 60.6536 seconds. Figure 13 data retrieval from the three AODV, OLSR, and ZRP protocols use 20 nodes. From the data taken, it can be seen that the AODV protocol has a record that the routing discovery time is faster than the OLSR and ZRP routing protocols. From the research that has been done for each tested protocol, AODV is superior because this protocol reacts immediately when a request occurs for TCP packet delivery. The ZRP protocol also does this, but it takes longer than AODV. OLSR protocol is the most prolonged protocol because, in the forming the routing table, you have to wait for the update interval periodically before sending TCP packets.

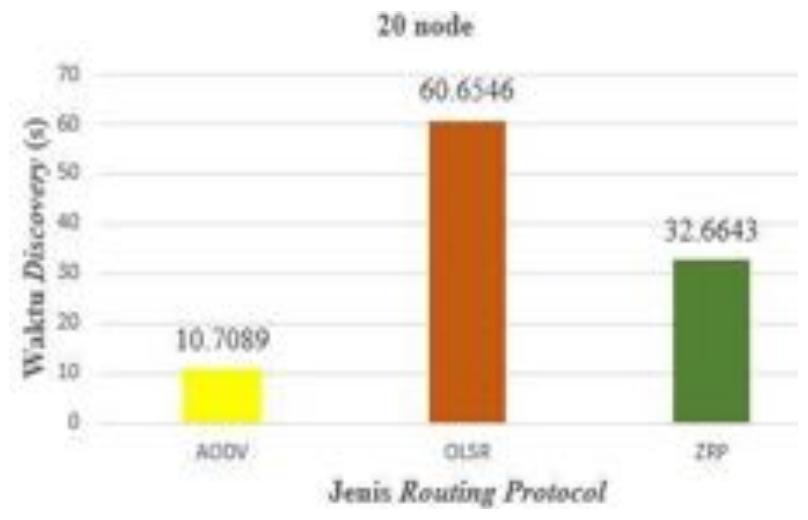

Fig. 14. Routing Discovery Time Graph for 30 Nodes

Figure 14 above shows that the AODV routing protocol has the lowest discovery time, which is 15.8675 seconds in delivery time using 30 nodes, the next is the ZRP protocol, which is 47.3314 seconds in delivery time and the last one is 69.3484 seconds. Retrieval of data from the three AODV, OLSR, and ZRP protocols using 30 nodes shows that the AODV protocol still has a record of faster routing discovery times like 20 nodes from the previous data. From the research that has been done using 30 nodes, it can be seen that the
AODV protocol is still superior to other protocols. However, compared to 20 nodes, this discovery time is a little longer due to the addition of nodes which make the sending process longer than the previous process.

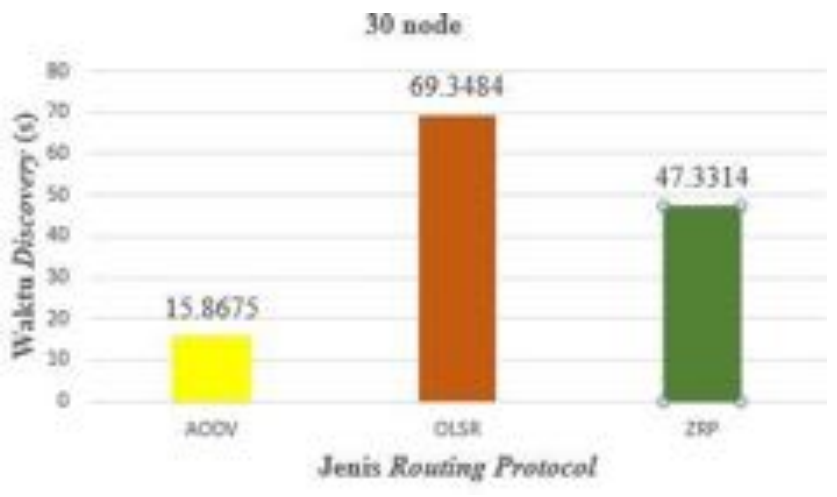

Fig. 15. Graph of Routing Discovery Time on 40 Nodes

From Figure 15 above, it can be seen that the AODV routing protocol has the lowest discovery time, which is 18.8912 seconds in delivery time using 30 nodes, the next is the ZRP protocol, which is 50.18 seconds in delivery time and the last one is 80.8578 seconds. From the data taken, it can be seen that the AODV protocol has a record of faster discovery times than OLSR and ZRP routing protocols.

Analysis of Average Discovery Time

Table 4 shows the routing discovery times of each protocol for 20, 30 and 40 nodes.

Figure 16, the AODV protocol has the best discovery time on the AODV protocol with the lowest time, namely 10.7089 s. The addition of nodes in AODV affects the value of the graph, which is getting more prominent; this is due to the influence of topology changes, which will make adjustments. The source node will send data to the destination node and impact the time of delivery, but it is not too severe.

Based on the data from the research that has been carried out, the results described above are obtained. Research conducted on the AODV, OLSR, and ZRP protocols to calculate the routing discovery speed of each protocol. There are three scenarios carried out to test the routing discovery time on AODV, OLSR, and ZRP protocols. The first uses 20 nodes, the second uses 30 nodes, and the third uses 40 nodes. Along with the increase in time and the increase in nodes, the resulting discovery time is getting bigger.

The addition of nodes in AODV affects the value of the larger graph. Due to the effect of changing nodes, which will make topology adjustments when the source node will send data to the destination node and impact the resulting discovery time. As the node increases, the resulting discovery time increases due to traffic congestion, which causes network congestion.

OLSR has the highest discovery time compared to AODV and ZRP; the addition of nodes affects the graph's value, which is increasing. It happened because the characteristics of the proactive class always update routes to all nodes periodically, thus making the discovery time value increase. The ZRP protocol has a second-high time after OLSR. The addition of nodes also affects the value of the ZRP delay, 
because the length of the route tracing on ZRP uses two protocol systems, namely proactive and reactive.

TABLE IV. ROUTING DISCOVERY TIMES of AODV, OLSR, ZRP
\begin{tabular}{|c|c|c|c|}
\hline \multirow{2}{*}{ Type of routing protocol } & \multicolumn{3}{|c|}{$\begin{array}{c}\text { routing discovery time } \\
\text { (s) }\end{array}$} \\
\cline { 2 - 4 } & $\mathbf{2 0}$ nodes & $\mathbf{3 0}$ nodes & $\mathbf{4 0}$ nodes \\
\hline AODV & 10.7089 & 15.8675 & 18.8912 \\
\hline OLSR & 60.6536 & 69.3484 & 80.8578 \\
\hline ZRP & 32.6643 & 47.3314 & 50.18 \\
\hline
\end{tabular}

The average discovery time for the three routing protocols is shown in the following Figure:

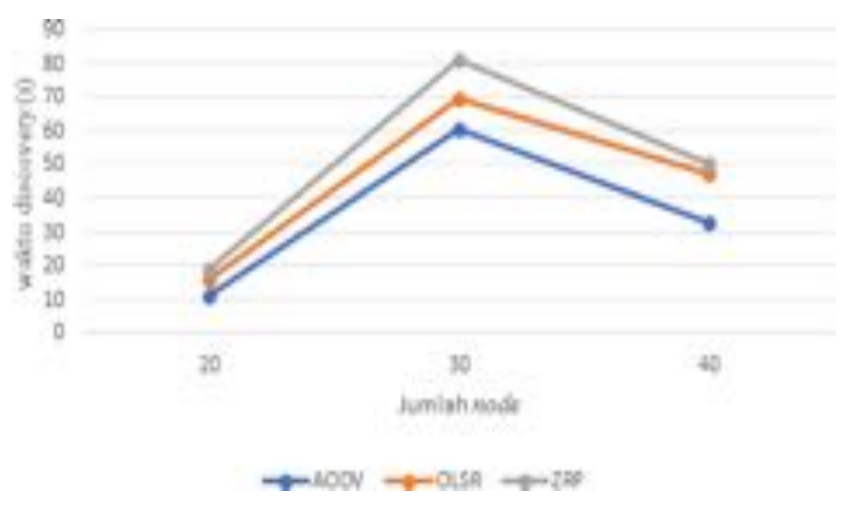

Fig. 16. Graph of Average Discovery Time

\section{CONCLUSION}

From the experimental results, 20 nodes AODV Routing Protocol has a faster and more limited routing discovery time, namely 10,7089 s. Meanwhile, the OLSR protocol has the highest discovery time, which is $60.6536 \mathrm{~s}$. And the ZRP protocol has a discovery time of $32,6643 \mathrm{~s}$. In the number of node 30 protocols that have the lowest time, AODV also is $15.8675 \mathrm{~s}$. OLSR protocol still has the highest discovery time, $69.3484 \mathrm{~s}$, and ZRP protocol has a discovery time of 47.3314 s. The experiment using 40 nodes as the discovery time also shows that the AODV protocol superior with the lowest time is $18.8912 \mathrm{~s}$. OLSR is the protocol with the highest discovery time of $80.8578 \mathrm{~s}$, and while the discovery time of ZRP is 50.18 s.
Increasing the number of nodes in each scenario produces data that is directly proportional to discovery time. The more nodes added to the three protocols, the longer the discovery time in information transmission. Based on the routing discovery time of each routing protocol, the AODV protocol is more suitable for networks because it has a low discovery time compared to the OLSR protocol, which has the highest discovery time and ZRP at the number of nodes 20,30 and 40 .

\section{REFERENCES}

[1] Purba D.U, R. Primananda, and K. Amron. "Analisis Kinerja Protokol Ad Hoc OnDemand Distance Vector (AODV) dan Fisheye State Routing (FSR) pada Mobile Ad Hoc Network," J. Teknol., vol. 2, no. 7, 2018.

[2] Yuliswar D, Sofia, N. H dan Tengku. A. R. Analisis Performansi Protokol Routing Tora dan ZRP pada Jaringan Wireless Mobile Ad Hoc Network (MANET) Dengan Menggunakan Model Trafik Tcp, Tugas Akhir. Badung: Teknik Telekomunikasi, Fakultas Teknik Elektro, Universitas Telkom, 2011.

[3] Fatkhurrozi, Widasari E. R. Bhawiyuga Adhitya. "Analisis Perbandingan Kinerja Protokol AOMDV, DSDV, Dan ZRP Sebagai Protokol Routing Pada Mobile Ad-Hoc Network (MANET)". Jurnal Pengembangan Teknologi Informasi dan Ilmu Komputer. Vol. 2, No. 10, hlm. 3671-3680, 2018.

[4] Aprillando, A. Cara Kerja dan Kinerja Protokol Optimized Link State Routing (OLSR)pada Mobile Ad hoc network (MANET), Tugas Akhir. Jakarta: Fakultas Teknik Unika AtmaJaya, 2007.

[5] Irawan, D. dan Roestam, R. Simulasi Model Jaringan Mobile Ad-Hoc (Manet) Dengan Ns-3, Badan Pengkajian dan Penerapan Teknologi. Jakarta, pp. 335-339, 2011.

[6] Perkins, Belding-Royer, and Das. Ad-Hoc On-Demand Distance Vector (AODV) Routing, University Of California, RFC 3561, IEFT Network Working Grup, Sun Microsystems Laboratories Advanced Development Grup Menlo Park, 2003.

[7] Rasha. T. K, Shwetha Vincent, Efficient Routing Protocol For Mobile Ad Hoc Network (MANET), Computer Science \& Technology Departement, Karunya University, Coimbatore, pp.3511-3625, 2013.

[8] Widyaningrum, Salman M. Analisis Kinerja Routing Protocol AODV OLSR dan TORA Terhadap Stabilitas Jaringan Pada Mobile Ad Hoc Network (MANET) Berbasis Ipv6, Tugas akhir. Yogyakarta: Universitas Islam Indonesia, 2016.

[9] Rasha. T. K, Shwetha Vincent. Efficient Routing Protocol For Mobile Ad Hoc Network (MANET), Computer Science \& Technology Departement, Karunya University, Coimbatore, 2013.

[10] Pujianto, Laurentius. Analisis Convergence Time Protokol Routing Dsdv Menggunakan Simulator Ns 3. Tugas Akhir. Yogyakarta: Fakultas Sains Dan Teknologi Universitas Sanata, 2014. 